\title{
Sobre as causas naturais que formam a base empírica do fenômeno dos turbilhões nas cosmogonias: dos Pré-Socráticos a René Descartes
}

\author{
(About the empirical foundation of the vortices theories on the Pre-Socratics cosmogonies) \\ José Plínio Baptista e Laércio Ferracioli
Universidade Federal do Espírito Santo, Campus Universitário de Goiabeiras, Departamento de Física, Vitória, ES, Brasil.

Recebido em 20/5/03; Manuscrito revisado recebido em 6/3/04; Aceito em 12/3/04

\begin{abstract}
Neste trabalho é apresentado um possível fundamento empírico para as teorias dos turbilhões que figuram em praticamente todas as teorias cosmogônicas dos pré-socráticos e mesmo presentes nas teorias de pensadores modernos como René Descartes e C. Huyghens.

Palavras-chave: cosmogonia, Pré-Socráticos, História da Física.

The aim of this work is to show possible empirical foundations for the phenomena of vortices presenting in almost all the cosmogonics theories of pre-socratics thinkers and also in theories of modern thinkers as René Descartes and C.Huyghens.
\end{abstract}

Keywords: cosmogony, Pré-Socratics, History of Physics.

\section{Introdução}

As teorias cosmogônicas surgiram com os chamados filósofos pré-socráticos, tais como, Thales (c. 624545 a.C.), Anaximandro (c. 610-545 a.C.) e Anaxímenes (c. 580-500 a.C.), todos oriundos da Ásia Menor. Suas idéias têm sido analisadas e debatidas por pesquisadores de História da Ciência e, sobretudo, por filósofos. Entre os filósofos modernos o tema foi debatido principalmente por Hegel (1770-1831), Nietsche (1844-1900) e Heidegger (18891976) [1] que analisaram estas idéias e concluíram que tratam-se de puras e consistentes filosofias.

No entanto, já em Aristóteles (c. 384-322 a.C.) desenha-se um ponto de vista diferente a respeito das obras daqueles pré-socráticos que receberam desse filósofo a designação de "físicos". Alguns pesquisadores em História da Ciência, dentre eles, Paul Tannery [2], destacam o fato das obras dos pré-socráticos terem sido analisadas por filósofos e as conclusões nunca terem provocado contestação, tendo sido tradicionalmente aceitas pelos historiadores da ciência. Entretanto, afirma Tannery, os fundamentos dos sistemas propostos por estes físicos nunca foram filosóficos, mas sim baseados em conhecimentos empíricos, portanto, de naturezas concretas e objetivas. Segundo historiadores da ciência é nesta fase que se inicia a construção da ciência no mundo ocidental.

O embasamento empírico das teorias dos pré-socráticos é explicitamente indicado por Aristóteles em seu tratado Os Céus [3]:

'... a forma da causação supõe que todos eles se baseiam na observação dos líquidos e do ar, nos quais os corpos maiores e mais pesados sempre se movem para o centro do turbilhão. Isto é pensado por todos

Enviar correspondência para Laércio Ferracioli. E-mail: laercio@cce. ufes.br os que tentam gerar os céus por este meio para explicar por que a Terra se situa no centro.'

É então, na opinião de Aristóteles, o turbilhão nos gases ou nos líquidos, o inspirador dos processos envolvidos naquelas propostas de cosmogonias. A figura do turbilhão, de fato, tem aparecido invariavelmente nas propostas de teorias que pretendem dar explicações sobre a origem do universo, inclusive nas teorias modernas.

Dessa forma, pode-se tentar compreender como, supostamente, os filósofos pré-socráticos se utilizaram de fenômenos naturais para elaborar suas teorias de criação da matéria. É sabido que os vórtices atmosféricos são fenômenos que acontecem com muita frequiência em certas regiões da Terra, enquanto raramente em outras. $\mathrm{O}$ mais importante e fundamental efeito para o uso deste processo na descrição da criação da matéria pela ação do turbilhão sobre a substância primordial é a compactação das partes pesadas como consequiência do seu confinamento no centro do turbilhão cósmico.

O processo da cosmogênese, proposto nas teorias dos pré-socráticos, se inicia pela instauração de um movimento rotacional no interior da substância primordial - o Ápeiron de Anaximandro, ou a substância formada pelas Spermas de Anaxágoras (c. 500-428 a.C.) ou ainda a nuvem cósmica de Átomos de Leucipo (c. 540-? a.C.)-Demócrito (c. 460370 a.C.) - que evolui rapidamente para um movimento turbilhonar. Este movimento turbilhonar concentra em seu núcleo as partes mais pesadas da matéria sintetizada da substância primordial e rejeita para a periferia do vórtice as partes mais leves.

Analisando o caso de Anaximandro onde o Ápeiron é a substância primordial que encerra todas as qualidades e seus contrários, o movimento turbilhonar tem como efeito separar estes pares e fundi-los gerando a matéria pesada, como a terra e a água, juntamente com os componentes 
mais leves, tais como o ar e o éter. Deste material sintetizado do Ápeiron, os componentes mais pesados, devido a ação do turbilhão, são levados para o centro do vórtice, enquanto as partes mais leves são expelidas para a periferia. Processos análogos são imaginados nas outras teorias cosmogônicas, diferenciando-se apenas no mecanismo de formação da matéria a partir da substância primordial, bem como na natureza desta substância.

Um aspecto delicado na escolha da base empírica deste mecanismo se refere justamente à sua principal característica, isto é, a dupla migração da matéria em direção ao centro do turbilhão de um lado e em direção a periferia do outro. Um processo semelhante é previsto na teoria cartesiana da criação do cosmos, porém, a natureza da sua substância primordial exige maior esforço imaginativo para que o processo seja bem compreendido. Para Descartes (1596-1650) o que é essencial na substância primordial é extensão e movimento e, conseqüientemente, o universo é uma entidade extensa, infinita e não vazia, lembrando que Descartes não admite a existência do vácuo [4].

Neste contexto, este artigo se propõe a lançar um olhar sobre as idéias acima descritas a partir do confronto das causas naturais que formam a base empírica do fenômeno dos turbilhões com a essência das idéias propostas em teorias cosmogônicas ao longo da evolução do pensamento da Física.

Dessa forma, inicialmente será apresentada uma descrição física atual e sucinta do fenômeno dos tornados que servirá de base para se compreender este confronto, seguida de uma análise que permita concluir como se dá o fenômeno da migração da matéria nas referidas teorias cosmogônicas finalizando com a apresentação e análise deste fenômeno na visão de Descartes e C. Huyghens (1629-1695).

\section{A Física do tornado}

Essa análise será feita examinando detalhadamente os fenômenos naturais que, supostamente, constituem as bases empíricas dos turbilhões das teorias cosmogônicas: os tornados e similares. De acordo com os especialistas [5], os tornados se formam e atuam através de um processo que pode ser resumido nas seguintes etapas:

1. Grandes massas de ar úmido e quente colidem com grandes massas de ar seco e frio. Desta interação resulta uma rápida precipitação do ar úmido liberando uma grande quantidade de energia térmica gerando uma zona de baixa densidade que, por ação do empuxo, se desloca para camadas superiores, deixando um "vácuo" atrás de si;

2. Grandes massas de ar das vizinhanças são "sugadas" pela zona de baixa pressão e se dirigem para o centro dela; entretanto, como são desviadas em direção, pela ação das forças de Coriolis, acabam num movimento de rotação em torno do núcleo;

3. A conservação do momento angular cria no núcleo uma zona de altíssima rotação, sendo constantemente alimentada pelas massas de ar que para aí são atraídas;

4. Esta zona de altíssima rotação acentua ainda mais a diferença de pressão entre este núcleo e as partes periféricas das massas de ar que gravitam em torno deste núcleo, intensificando o fluxo de partículas que "caem" em direção ao núcleo do turbilhão;

5. As porções de ar que giram em torno do centro do núcleo numa trajetória determinada pelo equilíbrio entre a força centrífuga e o gradiente de pressão na região, desenvolvem altíssimas velocidades lineares ${ }^{1}$. Matéria sólida que se encontrar no caminho destas massas de ar em movimento espiralado em torno do núcleo do turbilhão serão, inevitavelmente, arrastadas com violência para o centro do vórtice.

Estes tornados ocorrem com uma frequiência espantosa em regiões da América do Norte, sendo menos freqüentes na Europa, porém, não de todo ausentes. Estes fenômenos meteorológicos são também produzidos sobre as águas - mares ou lagos. No Brasil são chamados de trombas d'água. Fenômenos de mesma natureza ocorrem em terreno seco, onde o solo é superaquecido gerando áreas de alta temperatura e baixa pressão nas proximidades do solo: este tipo de vórtice é denominado de Poeira do Diabo ou Dust Devil. Enquanto nos dois casos anteriores os fenômenos vêm acompanhados de forte chuva, neste último o vórtice é seco. A dinâmica básica do seu funcionamento é a mesma em todos estes casos, isto é, o enorme gradiente de pressão gerado empurra, com violência, as grandes massas de ar para o centro do vórtice.

\section{Mecanismo de migração de matéria no turbilhão cósmico}

Em todas as cosmogonias este processo migratório que ocorre no turbilhão cósmico é o responsável pela criação da matéria que mobilia todo o universo. No contexto terrestre, as terras, as águas, os oceanos são formados no núcleo do vórtice como conseqüência da compactação da matéria primordial alimentada pela contínua migração para o centro por efeito do turbilhão. Já os componentes mais leves extraídos da substância primordial são, por sua vez, expelidos para a periferia do turbilhão para constituir as componentes gasosas do mundo, como o ar e o éter. Nesta perspectiva a constituição material de todo o universo é consequiência do contínuo processo turbilhonar: a Terra composta pelas rochas, mares, rios e montanhas são fabricados pelo núcleo turbilhonar; em contrapartida, o ar, o éter inflamado, os corpos celestes, estrelas, Sol, e planetas são originados das componentes leves expelidas para a periferia do turbilhão.

Do conhecimento da estrutura do turbilhão atmosférico, seja acima das águas ou em terreno seco, podemos admitir que este fenômeno meteorológico pode muito bem ter sido o inspirador do turbilhão cósmico dos filósofos pré-socráticos e dos filósofos mais modernos, principalmente no seu efeito compactante das massas no núcleo do turbilhão. Entretanto, a segunda parte da ação turbilhonar cósmica, responsável pelos componentes leves e celestiais do mundo, dificilmente poderia ser explicada diretamente pelo turbilhão atmosférico, pois neste caso, tanto a matéria pesada quanto as partes mais leves são igualmente levadas pela forte corrente em direção ao núcleo. A menos que seja 
possível imaginar alguma instabilidade que impeça as partes leves de se estabilizarem em órbitas equilibradas pela força centrífuga e pelo gradiente de pressão e que tenha como conseqüência a expulsão destas partes da região central do turbilhão.

Uma interpretação proposta recentemente [6,7], onde as componentes leves migrariam para a periferia através de um processo de percolação pelo meio poroso formado pelas componentes pesadas permite, em princípio, compreender esta parte da migração. Entretanto, neste modelo, as componentes mais pesadas, e que servem como meio poroso, se localizam na região central do vórtice por meio de um processo de acomodação, pois não há fluxo de partículas em direção ao núcleo. Este último aspecto dificulta a adoção integral deste modelo para representar completamente o mecanismo cósmico, apesar do mesmo oferecer explicação para a migração da matéria leve para a periferia.

No caso do turbilhão cósmico com modelo no tornado, poderíamos esboçar uma explicação para a migração em direção da periferia das partes mais leves sintetizadas da substância primordial. Poderíamos imaginar que num tornado pudesse se realizar uma ação tão violenta, intensa, contínua e prolongada do processo de compactação e que a intensa sucção de matéria acabaria por criar um vácuo nas vizinhanças do núcleo compactado que, neste estágio, estaria animado de grande velocidade de rotação. Esta alta rotação provocaria algum desprendimento de pequenas partes deste núcleo, partículas e gases, separando-as do núcleo compactado e expulsando-as para órbitas circulares em torno deste núcleo, dando origem assim aos planetas, estrelas, o ar e o éter. Este é o mecanismo imaginado por Anaxágoras para a formação, por exemplo, do Sol, visto como uma rocha arrancada da Terra pela força centrífuga e que se inflama ao girar no meio do ar ígneo a alta velocidade $^{2}$.

Este mecanismo que descreveria a migração para a periferia das componentes leves da matéria recém gerada no cosmos é, no entanto, fruto de uma mera suposição, uma vez que não há em todos os escritos dos pré-socráticos nem nos registros dos doxógrafos ${ }^{3}$, ou dos pesquisadores em História da Ciência, qualquer indicação que esta solução tenha sido proposta por aqueles filósofos. Entretanto, a visão empírica que eles exibem com clareza em seus fragmentos nos faz imaginar que as teorias propostas dos vórtices não devem ter sido apresentadas pela metade e sim completas, porém, certamente, esta parte das teorias propostas deve ter se extraviado ao longo da História.

\section{O turbilhão cartesiano}

Em 1662 Descartes publica 'O Mundo ou Tratado da Luz' apresentando sua filosofia cosmogônica onde descreve a teoria dos turbilhões com o objetivo de explicar a cria- ção da matéria do universo e, em seguida, a gravitação universal. Em sua teoria original Descartes descreve que o universo seria recoberto por um mosaico de turbilhões que mantém em cada vórtice a matéria sutil em rotação. Da fricção nas suas fronteiras estes turbilhões gerariam suficiente energia para criação da matéria que preenche nosso universo.

Igualmente, em cada turbilhão deveria ocorrer o processo de compactação da matéria mais pesada e formação de componentes mais leves que gravitariam em torno deste núcleo. Os sistemas planetários seriam mantidos pelos turbilhões que, no caso do sistema solar, fixariam o Sol no centro do sistema e conduziriam os planetas em suas trajetórias em torno deste Sol.

O embasamento empírico desta teoria está descrito na carta de Descartes à Mersenne [9], onde sugere ao seu correspondente que para compreender como a matéria sutil, que gira em torno da Terra, empurra os corpos pesados para o centro desta é suficiente realizar uma experiência simples colocando pequenas esferas de chumbo e de madeira em uma vasilha cilíndrica e fazendo-a girar em torno de um eixo que passa pelo seu centro. Se verificará, diz o filósofo, que as esferas de chumbo empurrarão as peças de madeira para o centro da vasilha [6].

Porém, a menos que tenha havido algum erro de tradução do original desta carta, encontramos na sua redação uma contradição ${ }^{4}$. Pode-se perceber facilmente que o resultado de sua experiência não confirma o que ele propõe, a princípio. Apesar disso, podemos também imaginar que Descartes tenha se inspirado nos fenômenos naturais, vórtices e tornados para elaborar sua teoria dos turbilhões. Entretanto, a interpretação dos processos que ocorrem nos turbilhões cartesianos por comparações simples com aqueles fenômenos atmosféricos é muito mais delicada. Muitas grandezas mecânicas, tais como pressão e densidade são dificilmente traduzíveis neste mundo preenchido pela matéria sutil, a extensão. Além do mais a noção de vácuo foi banida por Descartes.

\section{Newton e os turbilhões cartesianos}

A figura do turbilhão na teoria cartesiana está indissoluvelmente associada ao processo de geração do cosmos e também à manutenção e estabilidade dos sistemas planetários. A polêmica entre os newtonianos e os cartesianos, relativa a esse tema, foi também longa e vibrante. A principal crítica dos cartesianos com respeito à teoria de Isaac Newton (1642-1727) referia-se à figura da ação à distância implicada na sua teoria da gravitação. Para os cartesianos era uma idéia inaceitável do comportamento da natureza e, como ensinava Descartes, as ações entre as partes materiais devem, necessariamente, ser por contacto direto, impulsivas e nunca atrativas ${ }^{5}$.

2 Ver P.Tannery, obra citada mais acima.

3 Escritores antigos que, pela leitura direta dos escritos originais dos filósofos pré-socráticos, escreveram comentários sobre as teorias propostas. Os seus escritos constituem, modernamente, as únicas fontes de referências.

4 Este texto foi retirado do livro Estudos Galilaicos de Alexandre Koyré [8].

5 As discussões e controvérsias a respeito destes assuntos estão notavelmente descritas e analisadas em Études Newtoniennes, de Alexandre Koyré [9]. 
Newton não propôs nenhuma teoria cosmogônica, porém, a ação do turbilhão cartesiano na manutenção da dinâmica planetária confrontava-se diretamente com sua descrição gravitacional. Consequientemente isto levou Newton a analisar de perto a existência e funcionalidade dos turbilhões cartesianos. No Livro II, de sua obra Princípios Matemáticos de Filosofia Natural [10], na Seção IX e em função dos teoremas de números. 39, 40 e 41 e escólios, Newton examina o comportamento físico-matemático dos turbilhões.

Num turbilhão infinito, ou mesmo confinado em um vaso cilíndrico, gerado por uma esfera em rotação uniforme no interior de um fluido homogêneo, os tempos de rotação dos pontos do turbilhão variam na razão do quadrado das distâncias destes pontos ao centro do turbilhão ${ }^{6}$. Newton demonstrou que:

1. Se um corpo de mesma densidade que o fluido for arrastado pelo turbilhão, ele percorrerá órbitas circulares e terá período de rotação proporcional ao quadrado de sua distância ao centro do turbilhão;

2. Se um corpo de densidade maior que a do fluido turbilhonar, for arrastado por este, não realizará uma trajetória fechada e sim uma espiral tendendo a se afastar do centro do turbilhão;

3. Se um corpo de densidade menor que a do fluido for arrastado por este, percorrerá uma trajetória em espiral e se dirigindo ao centro do turbilhão;

4. Como os tempos de rotação das órbitas planetárias descobertas por Kepler são proporcionais à raiz cúbica dos quadrados das distâncias médias ao sol, Newton conclui que a ação dos turbilhões cartesianos está em contradição com as leis de Kepler.

O resultado desta análise mostra que os turbilhões cartesianos não se conformam às leis astronômicas: portanto, esta teoria foi rejeitada.

\section{Newton e os turbilhões de Huyghens}

O sistema filosófico de Descartes, com suas conseqüências na Física, Astronomia e na Matemática, exerceu grande influência na Europa seduzindo um grande número de pensadores. Uma das mais interessantes personalidades foi C. Huyghens, físico, matemático e inventor holandês. São de grande importância suas contribuições na Mecânica: além da determinação do centro de oscilações de sistemas de corpos, o teorema das forças vivas, a sua mais expressiva conquista foi a descoberta da força centrífuga no movimento circular de uma partícula.

A teoria do turbilhão de Huyghens não foi elaborada para usá-la na cosmogênese, mas sim na tentativa de explicar mecanicamente a gravitação, sem fazer apelo à noção, inadmissível por ele, da ação à distância contida na teoria planetária de Newton. Apesar da teoria de Huyghens usar o modelo cartesiano dos turbilhões ligeiramente modificado, a sua concepção da constituição do mundo diferia um pouco da visualizada por René Descartes.

Em primeiro lugar, Huyghens não aceitava o substratum universal cartesiano matéria sutil, formada pela extensão em movimento da matéria, mas supunha que o universo fosse infinitamente preenchido por minúsculas partículas em eterno movimento caótico (é um atomismo) ${ }^{7}$. Em torno de cada estrela ou planeta existiria um turbilhão "esférico" onde estas partículas realizariam intensos movimentos de rotação em todos os sentidos ao redor do corpo central. Os planos das trajetórias destas partículas se distribuiriam aleatoriamente, mas passantes pelo centro do corpo. Huyghens afirmava que, se no interior deste turbilhão esférico existissem fragmentos mais pesados de matéria, o movimento do turbilhão provocaria o deslocamento destas partes sólidas em direção ao corpo central. Esta seria, segundo ele, a explicação para a gravidade. Para compreender este fenômeno Huyghens propõe a realização de uma experiência simples, descrita por Ernst Mach (1838-1916) na sua obra Mecânica, página 155, [11]:

'...ele mergulha num vaso cilíndrico fechado e cheio de água, pedaços de cera de lacre, que, devido à sua densidade um pouco maior, vão se depositar no fundo do vaso. Este vaso sendo em seguida animado de um movimento de rotação, os pedaços de cera vão se colocar no bordo exterior. Cessando bruscamente a rotação do vaso, a água continuará a girar enquanto que os pedaços de cera, que repousam sobre o fundo e cujo movimento é mais rapidamente contrariado, são agora impelidos para o centro.'

Mach finaliza dizendo que Huyghens vê neste fenômeno a imagem da gravidade.

\section{Conclusão}

Pode-se observar que a figura do turbilhão aparece em quase todas as teorias cosmológicas elaboradas para descrever o nascimento do universo. Esta idéia, segundo se sabe, provém dos filósofos da Ásia Menor tendo como principais personagens Thales, Anaximandro e Anaxímenes. A maior parte dos filósofos gregos da Antigüidade que propuseram suas teorias cosmogônicas, além dos pré-socráticos da Ásia Menor, pode-se citar Heráclito (540-480 a.C.), Parmênides (c. 540-450 a.C.), Anaxágoras (c. 500428 a.C.), Leucipo (c. 540-? a.C.)-Demócrito (c. 460370 a.C.) e Empédocles (c. 490-439 a.C.). Porém, nem todos utilizaram os tornados como base empírica de suas teorias.

Todavia a analogia direta entre os turbilhões cósmicos e os vórtices atmosféricos justifica facilmente apenas parte do mecanismo gerador da matéria que mobilia nosso universo. Para se obter uma analogia completa seria necessária admitir a ocorrência de um processo especial: a formação de vácuo no entorno do turbilhão por conseqüência da sucção violenta da matéria adjacente ao núcleo, de forma

6 Neste caso a velocidade das partículas do turbilhão varia como $V=a / r$ Logo se a trajetória da partícula tiver comprimento igual a $2 \pi r$, então $t=2 \pi \mathrm{a}^{-1} r^{2}$.

7 O vácuo, na teoria de Huyghens, não foi definitivamente descartado, pois na sua teoria da luz havia a necessidade de um meio que propagasse suas ondas luminosas. 
a que partes menores que se desagregam do núcleo possam ser expulsas para a periferia do vórtice. Teríamos então a formação do ar envolvente, do éter dos espaços siderais, dos planetas e das estrelas. Teríamos aí a organização completa do cosmos grego. Porém, esta última parte é apenas uma suposição, pois não há registros nos fragmentos dos pré-socráticos nem nos escritos dos doxógrafos que façam referência a este tipo de interpretação. Esta parte das explicações relacionada ao emprego do turbilhão certamente, conforme mencionado mais acima, deve ter se perdido ao longo do tempo.

O emprego do turbilhão, entretanto, não se restringiu exclusivamente à elaboração de mecanismos de criação da matéria nas cosmogonias. Vê-se outras funções nas teorias de pensadores modernos, como por exemplo, a explicação mecânica da ação gravitacional proposta por C. Huyghens ${ }^{8}$. Como foi observado mais acima, Huyghens não aceitava a teoria da gravitação tal como Newton a apresentava por que, segundo sua justificativa, a atração à distância não poderia ser explicada mecanicamente. A sua teoria do turbilhão planetário foi uma tentativa neste sentido. Finalmente a teoria de Huyghens nos permite compreender um pouco melhor a afirmação de Aristóteles [3]:

'...que os céus se movendo em torno dela a alta velocidade, impede todo movimento da Terra como a água num copo ao qual é dado um movimento circular que mantém esta água no interior do copo.'

Portanto, a crença de que o movimento rotacional de um corpo ou de um sistema de corpos gera uma ação centrípeta, tanto mais intensa quanto maior for a velocidade de rotação, é muito antiga e Huyghens nada mais fez do que tentar encontrar razões que permitem compreender o sentido desta referência da parte de Aristóteles.

O presente artigo examina como o fenômeno dos turbilhões esteve presente na proposição de teorias cosmogônicas ao longo da evolução do pensamento da Física: dos pré-socráticos a pensadores modernos observa-se que, se não de todo apropriadamente explicada, a utilização deste fenômeno nessas teorias são aqui trazidas para uma reflexão na busca de um entendimento de um tema que demanda um maior aprofundamento histórico de suas origens e conseqüências.

\section{Agradecimento}

Este trabalho foi financiado parcialmente pelo $\mathrm{CNPq}$, CAPES e pelo FACITEC/CMT/PMV - Fundo de Apoio à Ciência e Tecnologia do Conselho Municipal de Ciência e Tecnologia do Município de Vitória, ES.

\section{Referências}

[1] F. Nietzche, Os Pré-Socráticos (In Os Pensadores, Editora Abril, São Paulo, 1985).

[2] P. Tannery, Pour l'Histoire de la Science Helène (Gauthier-Vellars, Paris, 1930).

[3] Aristóteles, in The Heavens, Enc. Britannica (The Great Books of the Western World, Enc. Britannica Inc., Chicago, 1989), v. 4.

[4] J.P. Baptista e L. Ferracioli, A Construção do Princípio de Inércia e do Conceito de Inércia Material. Revista Brasileira de Ensino de Física 22, 272 (2000).

[5] Informações obtidas em sites de Física da Atmosfera e Física dos Tornados. Vide, por exemplo, o site de busca www.yahoo.com em 'physics of tornadoes' e em particular www.stormchasing.nl e www.nssl.noaa.gov/NWSTornado.

[6] J.P. Baptista A Função do Movimento Rotacional nas Cosmogonias dos Pré-Socráticos. Revista Brasileira de Ensino de Física 25, no prelo (2003).

[7] J. Burnett, O Despertar da Filosofia Grega. (Siciliano, São Paulo, 1994).

[8] A. Koyré, Estudos Galilaicos. (Editora Dom Quixote, Lisboa, 1986).

[9] A. Koyré, Études Newtoniennes (Éditions Gallimard, Paris, 1964).

[10] I. Newton, in Mathematical Principles of Natural Philosophy, Enc. Britannica (The Great Books of the Western World, Enc. Britannica Inc, Chicago, 1989).

[11] E. Mach, La Mécanique (Librairie Scientifique J. Hermann, Paris, 1925) 